\title{
LEVANTAMENTO CENSITÁRIO DA ARBORIZAÇÃO URBANA VIÁRIA DE SENADOR GUIOMARD, ACRE
}

Álisson Sobrinho Maranho ${ }^{1}$;SheillyRaquelly Prado de Paula²; Érica Lima ${ }^{3}$; Ary Vieira de Paiva ${ }^{4}$; Aramis Pereira Alves²; Dyonatar Oliveira do Nascimento²

\section{RESUMO}

A avaliação da arborizaçãoauxilia no processo de planejamento e nas decisões referentes às técnicas de manejo que podem ser aplicadas. O objetivo deste trabalho foi realizar um levantamento censitário da arborização viária do município de senador Guiomard, Estado do Acre. Foram inventariadas todas as árvores da malha urbana, bem como posição de plantio e estado fitossanitário. As ruas e calçadas tiveram suas larguras medidas. Dentre as espécies identificadas, 16 são exóticas e 12 nativas. Dos indivíduos,88,3\% são de espécies exóticas. Foiobservada maior frequência das espécies Ficus benjamina (46,9\%), Roystonea oleracea (9,2\%), Mangifera indica (7\%), Syzygium malaccense (5,9\%) e Tecomastans (5,2\%). As ruas e calçadas são de larguras reduzidas, com média de 6,8 e 1,68 m, respectivamente. A arborização viária de Senador Guiomard é bastante deficiente, com maioria das espécies de origem exótica e alta frequência de indivíduos em poucas espécies. $\mathrm{O}$ Índice de Shannon-Wiener para Senador Guiomard foi de 2,24, que apresentou ainda apenas 6,2 indivíduos/km de calçada, indicando baixa diversidade e reduzida quantidade de árvores nas ruas da cidade, mostrando que é de extrema necessidade um planejamento e elaboração de projeto de arborização urbana para o município.

Palavras-chave:inventário; vias públicas; espécies nativas e exóticas; diagnóstico.

\section{CENSUS OF URBAN FOREST IN THE STREETS OF SENADOR GUIOMARD, ACRE}

\section{ABSTRACT}

The evaluation of the urban forest supports in the planning process and decisions regarding management techniques that can be applied. The study objective was to realize a census of urban forest in the streets of city of SenadorGuiomard, State of Acre, Brazil. There were inventoried all the trees of the urban area and position of planting and plant health. The streets and sidewalks had their measured widths. Among the species identified, 16 are native and 12 exotic. Of the individuals, 88.3\% are exotic species. There was a higher frequency of the species Ficus benjamina (46.9\%), Roystonea oleracea (9.2\%), Mangifera indica(7\%), Syzygium malaccense (5.9\%) and Tecomastans(5.2\%). The streets and sidewalks widths are reduced, with an average of 6.8 and $1.68 \mathrm{~m}$ respectively. The urban forest in the streets of Senador Guiomard showed to be very poor, with most species of exotic origin an high frequency of individuals in a few species. The Shannon-Wiener index of SenadorGuiomard was a 2.24, wich still had only 6.2 individuals/km of sidewalk, indicating low diversity and low number of trees on city streets, showing that it is a dire need for planning and project design of urban forest project for the city.

Keywords: inventory; public roads; native and exotic species; diagnosis.

\footnotetext{
${ }^{1}$ Eng. Florestal, Mestrando em Ecologia e Manejo de Recursos Naturais,Universidade Federal do Acre, Rio Branco, e-mail: alissonsobrinho@hotmail.com

${ }^{2}$ Graduando (a) em Engenharia Florestal, Centro de Ciências Biológicas e da Natureza, Universidade Federal do Acre, Rio Branco, e-mail: sheilly_prado@hotmail.com

${ }^{3}$ Eng. Florestal, Centro de Ciências Biológicas e da Natureza, Universidade Federal do Acre, Rio Branco, e-mail: ericajanu@hotmail.com

4 Eng. Agrônomo, Dr. Prof.do Centro de Ciências Biológicas e da Natureza, Universidade Federal do Acre, Diretor do Parque Zoobotânico/UFAC, Rio Branco, e-mail: arypaiva1@yahoo.com.br
} 


\section{INTRODUÇÃO}

A população urbana aumenta, as cidades crescem, e na maioria das vezes vão se expandindo sem um planejamento prévio de uso e ocupação do solo. Consequentemente ocorre a degradação do ambiente, impondo perda de qualidade de vida a seus moradores.

O ambiente urbano, artificial, cheio de construções, prédios, carros, pode ter esses fatores, que muitas vezes causam estresse ao homem citadino, amenizados com a presença de vegetação que quebra essa agressividade. Diante disso, pelos diversos benefícios comprovados que a arborização urbana proporciona, é de fundamental importância o seu estudo.

Atualmente a tendência é de aumentar a frequência de se analisar as cidades como sistemas integrados, vivos, onde os diferentes componentes interagem com o bom funcionamento do todo, dependendo da eficiência de cada uma das partes. Diante disso, cada componente tem que ser avaliado isoladamente e analisado dentro do sistema integral, a fim de que se possa identificar e localizar precisamente os problemas, e principalmente encontrar soluções que garantam à população urbana as condições mínimas para uma vida saudável (TEIXEIRA, 1999).

A arborização urbana é definida por Sanchotene (1994) como o conjunto da vegetação predominantemente arbórea natural ou cultivada, representada em áreas particulares, parques, praças, vias públicas e em áreas verdes complementares. Rossetti et al. (2010) ressaltam que a arborização urbana remete a um padrão de distribuição de árvores em um território urbano, podendose dizer que as árvores e vegetação associada em vias públicas e demais áreas livres de edificação são constituintes da floresta urbana atuando sobre o conforto humano no ambiente.

De acordo com Silva Filho et al. (2002) a arborização urbana atua sobre o conforto humano no ambiente por meio das características naturais das árvores, proporcionando ainda sombra para pedestres e veículos, redução da poluição sonora, melhoria da qualidade do ar, redução da amplitude térmica, abrigo para a avifauna e equilíbrio estético, que ameniza a diferença entre a escala humana e outros componentes arquitetônicos como prédios, muros e grandes avenidas, entre muitos outros.

Os vários benefícios que a arborização urbana pode fornecer estão condicionalmente ligados ao seu correto planejamento. Diante disso, o conhecimento e a análise das estruturas das cidades e suas funções, através das óticas econômica, social e ambiental, são pré-requisitos básicos para o planejamento e administração das áreas urbanas, na busca de melhores condições de vida para os seus habitantes, visto que pelos seus próprios objetivos, a arborização urbana assume importância particular (ROCHA et al., 2004).

Dantas e Souza (2004) ressaltam que planejar a arborização é indispensável para o desenvolvimento urbano, para que a atividade não venha a trazer prejuízos para o meio ambiente, considerando que a arborização é fator determinante da salubridade ambiental, por ter influência direta sobre o bem estar do homem, em virtude dos múltiplos benefícios que proporciona.

Com um planejamento apropriado, desenho e manejo, as árvores urbanas podem promover uma variedade de benefícios muito importantes para a sociedade. Entretanto, se uma boa gestão pode aumentar os benefícios, um manejo inadequado diminui esses benefícios e ainda pode aumentar os custos (NOWAK et al., 1998).

Aliado a um bom planejamento deve estar presente um plano de monitoramento, pois de acordo com Rocha et al. (2004), a deficiência no acompanhamento técnico pode acabar gerando à administração onerosos custos com podas, que na maioria das vezes ocorrem em caráter emergencial ao contrário de preventivo.

A escolha das espécies adequadas a serem utilizadas no meio urbano deve ser baseada em suas características: estruturais e estéticas -porte, arquitetura de copa, características físicas da madeira, morfologia, cor de folhas e flores, textura, estrutura e profundidade de raízes, aspectos do tronco (cor, ritidoma, presença de acúleos e espinhos); ecológicas -fenologia, estádio sucessional, ciclo de vida, adaptabilidade climática, 
tolerância ou resistência a pragas e doenças, tolerância ao estresse urbano, tolerância à sombra, tolerância a danos físicos e podas; químicas -princípios alergênicos e tóxicos; e genéticas - diversidade intraespecífica, resistência (PAIVA, 2009).

É essencial que a escolha da espécie a ser colocada no meio urbano seja realizada de forma correta e planejada, visto que o uso indevido de plantas pode acarretar em problemas futuros relacionados à população e empresas que prestam serviços de rede elétrica, telefonia, esgotos, entre outros (DANTAS; SOUZA, 2004).

Diante disso, o objetivo do presente trabalho foi realizar um levantamento censitário da arborização viária do município de Senador Guiomard, Estado do Acre, servindo como base para a elaboração de um projeto de arborização para o município.

\section{MATERIAL E MÉTODOS}

O presente trabalho foi realizado no município de Senador Guiomard, situado no Estado do Acre, no mês de junho de 2011.

\section{Área de estudo}

O Estado do Acre, antes território pertencente à Bolívia, foi incorporado ao Brasil em 1903, com a assinatura do Tratado de Petrópolis. Está situado no extremo sudoeste da Amazônia brasileira, entre as latitudes de $07^{\circ} 07 \mathrm{~S}$ e $11^{\circ} 08 \mathrm{~S}$, e as longitudes de $66^{\circ} 30 \mathrm{~W}$ e $74^{\circ} \mathrm{WGr}$. Sua superfície territorial é de 164.122,280 km² e sua extensão é de $445 \mathrm{~km}$ no sentido norte-sul e $809 \mathrm{~km}$ entre os extremos Leste-Oeste. O Estado faz fronteiras internacionais com o Peru e a Bolívia e, nacionais com os Estados do Amazonas e Rondônia (ACRE, 2006; IBGE, 2010). O Acre possui 732.793 habitantes, com a maior concentração populacional na capital do Estado Rio Branco, com 335.796 habitantes (IBGE, 2010).

Os principais solos do Acre, em ordem decrescente de expressão territorial, são: ARGISSOLOS, CAMBISSOLOS, LUVISSOLOS, GLEISSOLOS, LATOSSOLOS, VERTISSOLOS, PLINTOSSOLOS e NEOSSOLOS. Os solos do Acre apresentam características próprias principalmente por serem de uma região de acúmulo de sedimentos oriundos da Cordilheira dos Andes, o que confere a diversidade desses solos e características vérticas e de eutrofismo, pouco comuns na Amazônia (ACRE, 2006).

Predominam no Estado duas grandes Regiões Fitoecológicas: a Floresta Ombrófila Densa e a Floresta Ombrófila Aberta. Em uma pequena extensão existe também uma terceira, a Campinarana, restrita à parte noroeste do Estado. O clima é quente e úmido com duas estações: seca e chuvosa. A estação seca estende-se de maio a outubro. A estação chuvosa caracteriza-se por chuvas constantes, prolongando-se de novembro a abril. A circulação atmosférica regional é caracterizada pela atuação da Massa de Ar Equatorial Continental durante todo o ano. Os totais pluviométricos anuais variam de $1600 \mathrm{~mm}$ e $2750 \mathrm{~mm}$ e tendem a aumentar no sentido sudeste-noroeste. A temperatura média anual está em torno de $24,5^{\circ} \mathrm{C}$, enquanto que a temperatura máxima fica em torno de $32^{\circ} \mathrm{C}$ (ACRE, 2006).

\section{Senador Guiomard}

O município de Senador Guiomard (Figura 1) está situado há 24 km da capital do Estado, Rio Branco,possui 20.179 habitantes numa área territorial de 2.321,452 km², com densidade demográfica de 8,69 habitantes $/ \mathrm{km}^{2}$, sendo que 63\% da população é urbana (IBGE, 2010). 
Figura 1. Imagem aérea do município de Senador Guiomard, Acre, 2006

Figure 1. Aerial view of city of SenadorGuiomard, Acre, 2006

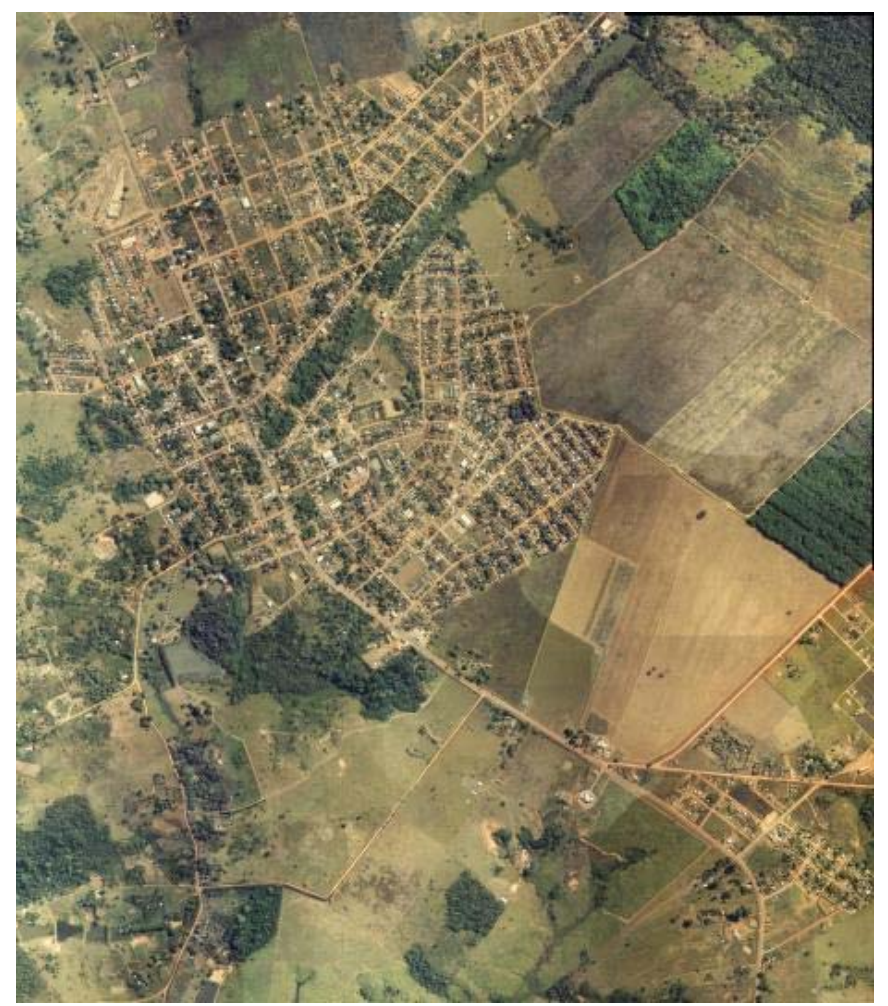

(Fonte: SEMA/AC).

(Source: SEMA/AC).

\section{Descrição do método}

O método utilizado foi o levantamento censitário das árvores, ruas, calçadas e posição da rede elétrica do município.

Em relação às ruas e calçadas, foi observado se apresentavam ou não pavimentação, sua largura e o comprimento, sendo que a largura foi obtida através de medição direta com auxílio de uma trena graduada em centímetros e o comprimento foi determinado com auxílio do programa AutoCAD, utilizando de imagem aérea da cidade. Foi realizada também uma análise descritiva destes dois parâmetros utilizando-se do programa estatístico Assistat 7.6 (SILVA, 2011).

As árvores foram inventariadas e analisadas quanto a sua localização e estado fitossanitário, sendo classificadas entre boa, regular, muito deformada e morta. A identificação das espécies foi baseada no sistema de classificação APG III (2009).

Foi gerado para a cidade de Senador Guiomard um Índice de Diversidade de Shannon-Wiener (H'), citados por Gomide et al. (2006), conforme descrito a seguir.

Indice de Shamnon- Wienten $H--\sum_{n=1}^{\mathrm{S}} \frac{\mathrm{n}}{\mathrm{N}} \ln \frac{\mathrm{n}_{\mathrm{i}}}{\mathrm{N}}$

Em que:

$\mathrm{S}$ = número de espécies amostradas;

$\mathrm{N}$ = número total de indivíduos amostrados;

$\mathrm{n}_{\mathrm{i}}=$ número de indivíduos amostrados para a i-ésima espécie;

$\ln =$ logaritmo neperiano;

Para determinar a posição em que a rede elétrica estava situada convencionou-se que a entrada da cidade seria o referencial. Nas ruas paralelas ao sentido entrada-saída da 
cidade, um membro da equipe se posicionou de costas pra entrada da cidade e nas ruas perpendiculares ao mesmo sentido apontou-se a mão direita para a entrada da cidade, com isso foi possível determinar se a rede elétrica estava do lado direito ou esquerdo da via. Dado este importante para construção do desenho e planejamento de plantio das árvores.

Para confeccionar o desenho da cidade utilizou-se o programa gráfico AutoCAD e uma imagem aérea da cidade, considerando todas as informações obtidas em campo.

\section{RESULTADOS E DISCUSSÃO}

O levantamento censitário realizado no município de Senador Guiomard resultou na observação de 426 indivíduos nas calçadas, distribuídos em 14 famílias botânicas (Tabela 1).

Dentre as espécies identificadas, 16 são exóticas e 12 nativas. Diante disso, Paiva et al. (2010) comentam que é tecnicamente recomendável o uso de espécies nativas da região trabalhada sob o ponto de vista ecológico adaptativo e funcional, principalmente para que se possa garantir relações ecológicas co-evolutivas e genéticas, de dispersão de propágulos (pólen e sementes) envolvendo fauna e flora dentro do ambiente urbano e também para conservação de material genético autóctone.

Em levantamentos de ocorrência de espécies florestais no Acre, tendo como base inventários florestais e levantamentos florísticos anteriormente realizados, Araújo e Silva (2000) encontraram 786 espécies nativas, no entanto, de acordo com Paiva et al. (2010) este número pode ultrapassar cerca de 3.000 espécies, já que somente uma parte das florestas do Estado foi inventariada, apontando o grande potencial de espécies para o meio urbano, bem como a necessidade de pesquisas que possam subsidiar a sua utilização.

Daly e Silveira (2008) revelam que o Estado do Acre possui uma diversidade biológica impressionante, detendo mais de 4.000 taxa de plantas vasculares e 156 espécies de plantas não vasculares, excluindo algas, e estimam ainda que este número pode dobrar nos próximos anos.

Diante desse grande potencial de espécies arbóreas da flora do Acre, as espécies nativas deveriam ser priorizadas em projetos de arborização urbana, pois além de todas essas funções, uma cidade arborizada com espécies características da sua região, tornaria este ambiente singular, com aspectos diferenciados de outras cidades e muito mais atrativos.

Tabela 1. Espécies encontradas nas vias de Senador Guiomard, Estado do Acre

Table 1.Species found in the streets of SenadorGuiomard, State of Acre

\begin{tabular}{|c|c|c|c|}
\hline Espécie & Nome vulgar & Hábito & Origem $^{(1)}$ \\
\hline \multicolumn{4}{|l|}{ Anacardiaceae } \\
\hline Anacardium occidentale L. & Cajueiro & Árvore & $\mathrm{n}$ \\
\hline Mangifera indica L. & Mangueira & Árvore & e \\
\hline \multicolumn{4}{|l|}{ Annonaceae } \\
\hline Annona muricata L. & Graviola & Árvore & e \\
\hline \multicolumn{4}{|l|}{ Arecaceae } \\
\hline Caryotaurens L. & Palmeira-rabo-de-peixe & Palmeira & e \\
\hline Roystonea oleracea O. F. Cook & Palmeira imperial & Palmeira & e \\
\hline \multicolumn{4}{|l|}{ Bignoniaceae } \\
\hline Handroanthus impetiginosusMattos & Ipê-roxo & Árvore & $\mathrm{n}$ \\
\hline
\end{tabular}




\begin{tabular}{|c|c|c|c|}
\hline Handroanthus sp. & Ipê & Árvore & $\mathrm{n}$ \\
\hline Tecomastans (L) Juss. exKunth & Ipê-de-jardim & Arbusto & $\mathrm{e}$ \\
\hline \multicolumn{4}{|l|}{ Combretaceae } \\
\hline Terminalia catappa $\mathrm{L}$. & Castanhola & Árvore & $\mathrm{e}$ \\
\hline \multicolumn{4}{|l|}{ Euphorbiaceae } \\
\hline $\begin{array}{l}\text { Hevea brasiliensis (Willd. ex A.Juss.) } \\
\text { Müll.Arg. }\end{array}$ & Seringueira & Árvore & $\mathrm{n}$ \\
\hline \multicolumn{4}{|l|}{ Fabaceae } \\
\hline Delonix regia (Bojer ex Hook.) Raf. & Flamboyant & Árvore & $\mathrm{e}$ \\
\hline Erythrina indicavar.picta & Brasileirinho & Árvore & $\mathrm{e}$ \\
\hline Caesalpinia ferrea (Tul.) Martius & Jucá & Árvore & $\mathrm{n}$ \\
\hline Caesalpinia peltophoroides Benth. & Sibipiruna & Árvore & $\mathrm{n}$ \\
\hline Caesalpinia pulcherrima (L.) Sw. & Flamboyantzinho & Árvore & $\mathrm{e}$ \\
\hline Senna sp. & Senna sp. & Árvore & $\mathrm{n}$ \\
\hline Clitoria fairchildiana R. A. Howard & Sombreiro & Árvore & $\mathrm{n}$ \\
\hline Adenanthera pavonina L. & Olho-de-pavão & Árvore & e \\
\hline \multicolumn{4}{|l|}{ Mapighiaceae } \\
\hline Lophantera lactescens Ducke & Lofantera-da-Amazônia & Árvore & $\mathrm{n}$ \\
\hline \multicolumn{4}{|l|}{ Malvaceae } \\
\hline Pachira aquatica Aubl. & Munguba & Árvore & $\mathrm{n}$ \\
\hline \multicolumn{4}{|l|}{ Moraceae } \\
\hline Cedrelasp. & Cedro & Árvore & $\mathrm{n}$ \\
\hline Ficus benjamina L. & Ficus & Árvore & e \\
\hline \multicolumn{4}{|l|}{ Myrtaceae } \\
\hline Psidium guajava $\mathrm{L}$. & Goiaba & Árvore & $\mathrm{n}$ \\
\hline Syzygium cumini (L.) Skeels & Jamelão & Árvore & $\mathrm{e}$ \\
\hline $\begin{array}{l}\text { Syzygium malaccense (L.) Merr. \& L. M. } \\
\text { Perry }\end{array}$ & Jambo & Árvore & $\mathrm{e}$ \\
\hline \multicolumn{4}{|l|}{ Oxalidaceae } \\
\hline Averrhoa carambola L. & Carambola & Árvore & $\mathrm{e}$ \\
\hline \multicolumn{4}{|l|}{ Rubiaceae } \\
\hline Gardeniajasminoides J. Ellis & Jasmim do Cabo & Arbusto & $\mathrm{e}$ \\
\hline \multicolumn{4}{|l|}{ Rutaceae } \\
\hline Murrayaexotica L. & Falsa Murta & Árvore & $\mathrm{e}$ \\
\hline \multicolumn{4}{|l|}{ Não identificadas } \\
\hline Sp.1 & $\mathrm{Ni}^{(2)}$ & - & - \\
\hline Sp.2 & ni & - & - \\
\hline Sp.3 & ni & - & - \\
\hline Sp.4 & ni & - & - \\
\hline Sp.5 & ni & - & - \\
\hline Sp.6 & ni & - & - \\
\hline Sp.7 & ni & - & - \\
\hline Sp.8 & ni & - & - \\
\hline Sp.9 & ni & - & - \\
\hline
\end{tabular}

(1) n: nativa; e: exótica;

(2) Espécie não identificada. 
Algumas espécies não puderam ser identificadas, devido principalmente aos efeitos de poda drástica realizadas nos indivíduos presentes nas vias públicas do município.

De todos os indivíduos identificados apenas $11,7 \%$ são de espécies nativas contra 88,3\% de espécies exóticas, havendo, portanto, uma grande desproporcionalidade na frequência dos indivíduos e espécies plantadas nas calçadas do município de Senador Guiomard.

Em trabalho semelhante realizado nas cidades de Colíder e Matupá, Estado do Mato Grosso, Almeida e Rondon Neto (2010) encontraram 64,7\% de espécies exóticas plantadas nas vias das cidades, num total de 547 indivíduos, sendo as espécies mais frequentes Licania tomentosa (73,1\%), Ficus benjamina (6,6\%) e Pachiraaquatica (4,2\%). Na Estância de Águas de São Pedro em São Paulo, Bortoleto et al. (2007) inventariaram 161 espécies, entre árvores, arbusto e palmeiras, que dentre estas $61,33 \%$ eram exóticas, com maior frequência da espécies Caesalpinia pluviosa (13,66\%).Na cidade de Aracaju, Sergipe, Santos et al. (2011), fizeram um levantamento da arborização das principais avenidas e encontraram 66 espécies, dentre as mais frequentes Pithecellobiumdulce (22,61\%) e Ficus benjamina (18,69\%), sendo que do total, $61 \%$ representam espécies exóticas.

Em levantamento realizado na Região Sul do País, Andreatta et al. (2011), encontraram nas avenidas de Santa Maria, 2.465 indivíduos, distribuídos em 95 espécies, sendo a maioria exótica (65,89\%). Lima e Silva Júnior (2010) encontraram nas ruas de Brasília - DF, 118 espécies arbóreas, sendo a maior frequência da espécie Mangifera indica (8,26\%), Spathodea campanulata (8,01\%) e Caesalpinia pluviosa (7,17\%), com predominância de espécies exóticas.
O que se observou nas ruas de Senador Guiomard foiuma alta frequência de indivíduos em poucas espécies (Figura 2), especialmente Ficus benjamina (46,9\%), Roystonea oleracea (9,2\%), Mangifera indica (7\%), Syzygium malaccense (5,9\%) e Tecomastans (5,2\%).

Algumas espéciesmerecem atenção por possuírem alta capacidade de propagação e estabelecimento, constituindo-se de planta invasora de áreas abertas, podendo assim interferir e mesmo prejudicar ou impedir os processos de sucessão vegetal natural, como é o caso da exótica Tecomainstans (PAIVA et al., 2010), que apareceu com frequência considerável nas ruas da cidade de Senador Guiomard.

O número de espécies plantadas nas vias de Senador Guiomard é muito reduzido, além da marcante presença de muitos indivíduos de poucas espécies, o que é verificado também pelo Índice de Shannon-Wiener calculado que foi de 2,24. O índice aponta para a baixa diversidade de espécies, estando muito inferior ao encontrado em algumas cidades brasileiras como em São Carlos - SP, que segundo Sucomine e Sales (2010) foi de 3,18, em Colorado - RS de 2,95 (RABER; REBELATO, 2010), 2,91 em Assis - SP (ROSSATO et al., 2008), e 3,89 em Cosmópolis - SP (PAIVA, 2009).

A Sociedade Brasileira de Arborização Urbana reconhece como um número ideal pelo menos 100 indivíduos por km de calçada (PAIVA, 2009). Sendo assim, Senador Guiomard apresentou 6,2 indivíduos/km de calçada, assemelhando-se à cidade de Rio Branco - AC (4,57 indivíduos $/ \mathrm{km}$ de calçada), que segundo Paiva et al. (2010) apresenta um dos menores índices de árvores por km de calçada do Brasil.Em Manaus-AM Costa e Higuchi (1999) obtiveram 20 árvores/km de calçada. Rossatoet al. (2008) encontraram 37,87 indivíduos/km de calçada na cidade de Assis - SP.

Figura 2. Frequência (\%) das espécies encontradas nas vias de S. Guiomard, Acre

Figure 2.Frequency (\%) of species found in the streets of S. Guiomard, Acre 


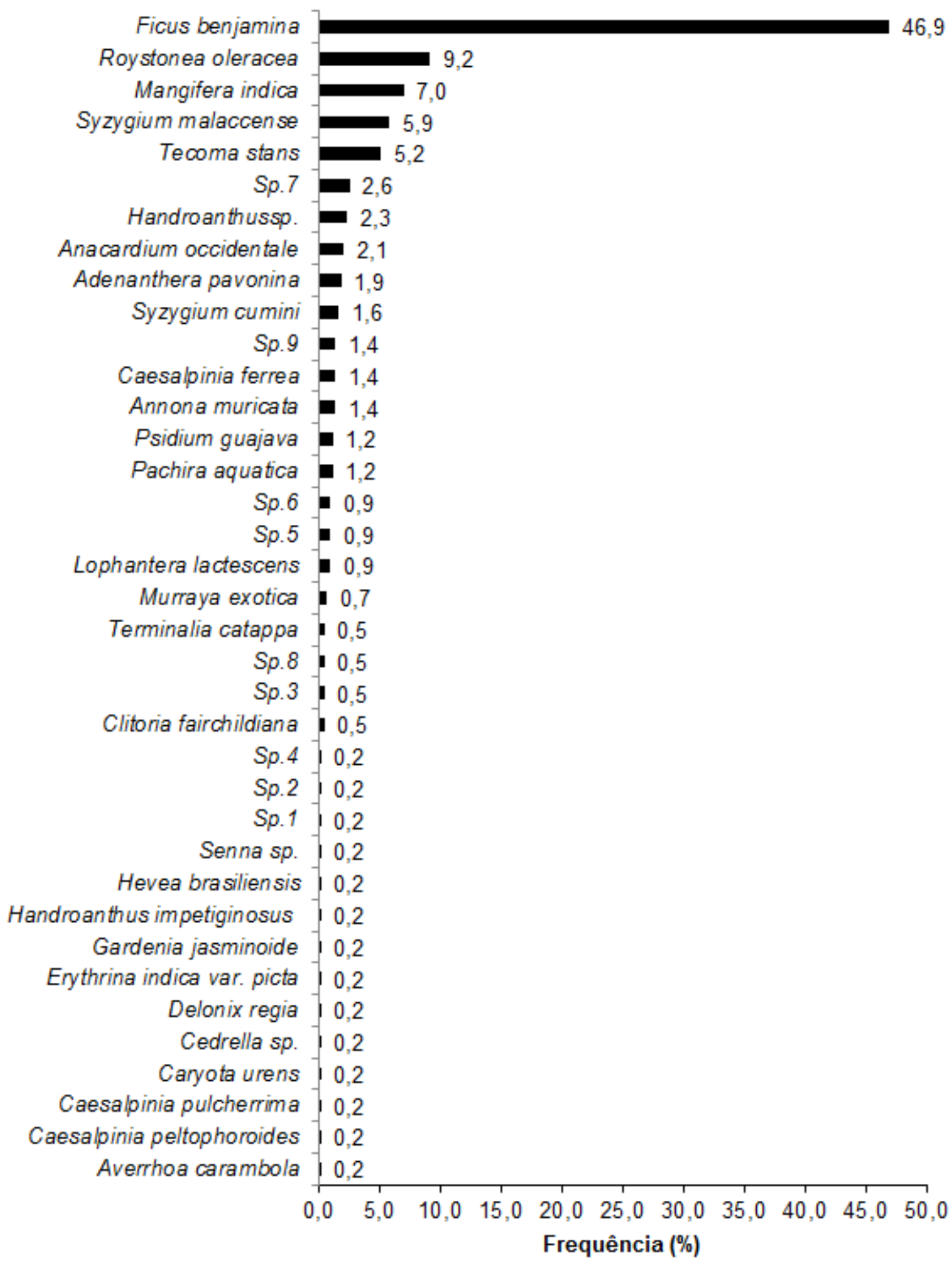

Na Tabela 2 constam algumas espécies nativas encontradas na literatura, que são aptas para arborização viária de Senador Guiomard, com informações de porte quando adulto e recomendações de locais de plantio, de acordo com trabalho de levantamento de espécies nativas com potencial para arborização urbana no Estado do Acre, realizado por Ribeiro e Paiva (2010). 
Tabela2.Espécies aptas para arborização viária de Senador Guiomard, Acre

Table 2.Species suitable for arborization of road of Senator Guiomard, Acre

\begin{tabular}{|c|c|c|c|}
\hline Espécie & Nome comum & Porte & Local \\
\hline Cordia alliodora (Ruiz \&Pav.) Cham. & Freijó & Médio a Grande & $\begin{array}{l}\text { Ruas sem fiação e } \\
\text { praças }\end{array}$ \\
\hline Alchornea discolorPoepp. & Supiarana & Pequeno a grande & $\begin{array}{l}\text { Ruas estreitas e sob } \\
\text { fiação elétrica }\end{array}$ \\
\hline Alchornea castaneifolia(Willd.) A.Juss. & Urana & Pequeno porte & Mata ciliar \\
\hline Erythrina vernaVell. & Mulungu & Grande/decídua & Parques e jardins \\
\hline Senna multijuga (Rich.) H.S.Irwin\& Barneby & Flor de São João & Médio a grande & $\begin{array}{l}\text { Ruas estreitas e sob } \\
\text { fiação }\end{array}$ \\
\hline Senna silvestris (Vell.) H.S.Irwin\& Barneby & $\begin{array}{l}\text { Fedegoso-do- } \\
\text { mato }\end{array}$ & Médio a grande & $\begin{array}{l}\text { Ruas estreitas e sob } \\
\text { fiação }\end{array}$ \\
\hline Amburana acreana (Ducke) A.C.Sm. & Cerejeira & Grande & Paisagismo \\
\hline Clitoria arboreaBenth.var.arborea & Palheteira & Médio a grande & $\begin{array}{l}\text { Fornece bom } \\
\text { sombreamento }\end{array}$ \\
\hline $\begin{array}{l}\text { Schizolobiumparahybavar.amazonicum(Huber } \\
\text { ex Ducke) Barneby }\end{array}$ & Canafístula & Grande & Rodovias e parques \\
\hline Parkiapendula(Willd.) Benth. exWalp. & Angico & Grande & $\begin{array}{l}\text { Grandes avenidas e } \\
\text { rodovias }\end{array}$ \\
\hline Casearia decandra Jacq. & Pitumba & Pequeno & Sob rede elétrica \\
\hline Gustavia augusta L. & Jeniparana & Pequeno a Médio & $\begin{array}{l}\text { Ruas estreitas e sob } \\
\text { fiação elétrica }\end{array}$ \\
\hline PhysocalymmascaberrimumPohl & $\begin{array}{l}\text { Itaúba-de- } \\
\text { capoeira }\end{array}$ & Médio & Parques e jardins \\
\hline Calycophyllumspruceanum(Benth.) K.Schum. & Mulateiro & Grande & $\begin{array}{l}\text { Parques, praças e } \\
\text { rodovias }\end{array}$ \\
\hline Lophanthera lactescens Ducke & $\begin{array}{l}\text { Lofantera da } \\
\text { Amazônia }\end{array}$ & Médio a grande & Ruas sem fiação \\
\hline Jacarandacopaia(Aubl.) D.Don & Marupá & Grande & $\begin{array}{l}\text { Parques, avenidas e } \\
\text { rodovias }\end{array}$ \\
\hline Handroanthus impetiginosusMattos & Pau-d’arco-roxo & Médio a grande & Praças, ruas, avenidas \\
\hline $\begin{array}{c}\text { Handroanthus serratifolius (A.H.Gentry) } \\
\text { S.Grose }\end{array}$ & $\begin{array}{l}\text { Pau-d'arco- } \\
\text { amarelo }\end{array}$ & Médio a grande & Praças, ruas, avenidas \\
\hline Ormosiagrandiflora(Tul.) Rudd & Tento & Pequeno & $\begin{array}{l}\text { Bom sombreamento, } \\
\text { ruas e avenidas }\end{array}$ \\
\hline
\end{tabular}

(Fonte: Adaptado de RIBEIRO; PAIVA, 2010)

(Source: Adapted of RIBEIRO; PAIVA, 2010)

Diante da grande biodiversidade do Estado, a prioridade poderia ser dada para as espécies características da região, como forma de manter as peculiaridades de cada município, a fim de conservar também todos os benefícios que uma arborização bem planejada pode oferecer ao homem citadino.
Quanto ao estado fitossanitário dos indivíduos, 47,2\% se mostraram em bom estado, 49,8\% foram classificados como regular devido principalmente aos efeitos de podas realizadas, 2,8\% apresentaram-se muito deformadas e $0,2 \%$ como mortos. 
Referente ao levantamento do tamanho de ruas e foi realizada e pode ser verificada na Tabela 3 .

calçadas, uma análise descritiva das larguras dos mesmas

Tabela 3. Análise descritiva das larguras de vias públicas e calçadas de S. Guiomard, Acre

Table 3.Descriptive analysis of the widths of roads and sidewalks of S. Guiomard, Acre

\begin{tabular}{ccccc}
\hline \multirow{2}{*}{ Instrumento } & \multicolumn{4}{c}{ Largura (m) } \\
\cline { 2 - 5 } & Mínimo & Máximo & Média & CV\%* \\
\hline Ruas & 4,64 & 11,0 & $6,8 \pm 0,18$ & 15,03 \\
Calçadas & 0,90 & 2,9 & $1,68 \pm 0,08$ & 23,01 \\
\hline
\end{tabular}

${ }^{*}$ CV: Coeficiente de Variação.

*CV: VariationCoefficient.

Como verificado na Tabela 3 , as ruas de Senador Guiomard são de larguras reduzidas, implicando na implantação de calçadas maiores, que neste caso também se apresentaram em dimensões reduzidas com médias de 1,68 metros. Sendo assim, é dificultoso o plantio de árvores de elevado porte, pois além de trazer problemas de danos nessas calçadas, poderia também dificultar a acessibilidade dos transeuntes.

Diante disso, a escolha correta das espécies a se colocar nas vias públicas adquire grande importância, devido a esses e outros fatores, para que não venha trazer prejuízos ao contrário de benefícios que deveriam prestar para a população.

Quanto às ruas de Senador Guiomard, $72 \%$ delas são pavimentadas, e $75,4 \%$ possuem calçadas. Das ruas que apresentam calçadas, $75 \%$ das calçadas são pavimentadas.

Resultado semelhante foi obtido por Araújo et al. (2009) em Campina Grande-PB, onde a largura das ruas variou de 7,0 a 8,0 m, enquanto a largura das calçadas variou de 1,9 a $2,8 \mathrm{~m}$.

A parte mais arborizada da cidade encontra-se no Centro, por possuir uma grande avenida com árvores plantadas nas calçadas e no canteiro central, ocorrendo principalmente a espécie palmeira imperial (exótica) nesta região.

A partir da coleta de todos estes parâmetros foi feito um desenho da malha urbana de Senador Guiomard com a intenção de projetar uma arborizaçãopara $100 \%$ das ruas do município (Figura 3). 
Figura 3. Projeto de arborização das vias públicas de Senador Guiomard, Acre

Figure 3.Street arborization project of SenadorGuiomard, Acre

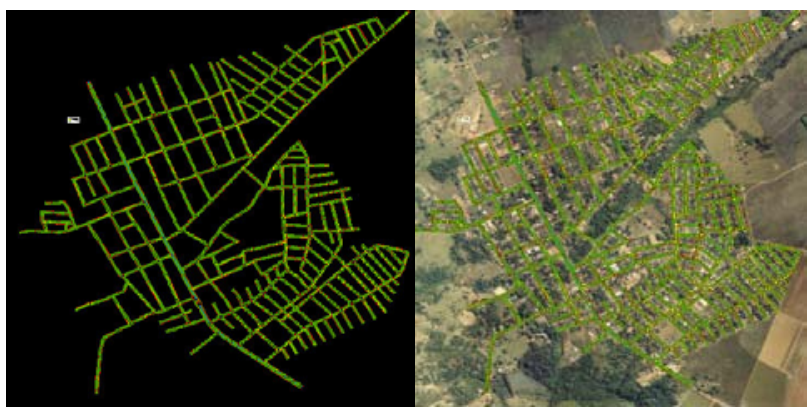

Para construção do desenho da arborização viária foram considerados alguns aspectos referentes principalmente ao porte dos indivíduos arbóreos, dimensão das calçadas e posição da rede elétrica, como pode ser observado em detalhe na Figura 4.

Figura 4. Detalhe do projeto de arborização viária de Senador Guiomard, Acre

Figure 4. Detail of the project of arborization of the streets of SenadorGuiomard, Acre

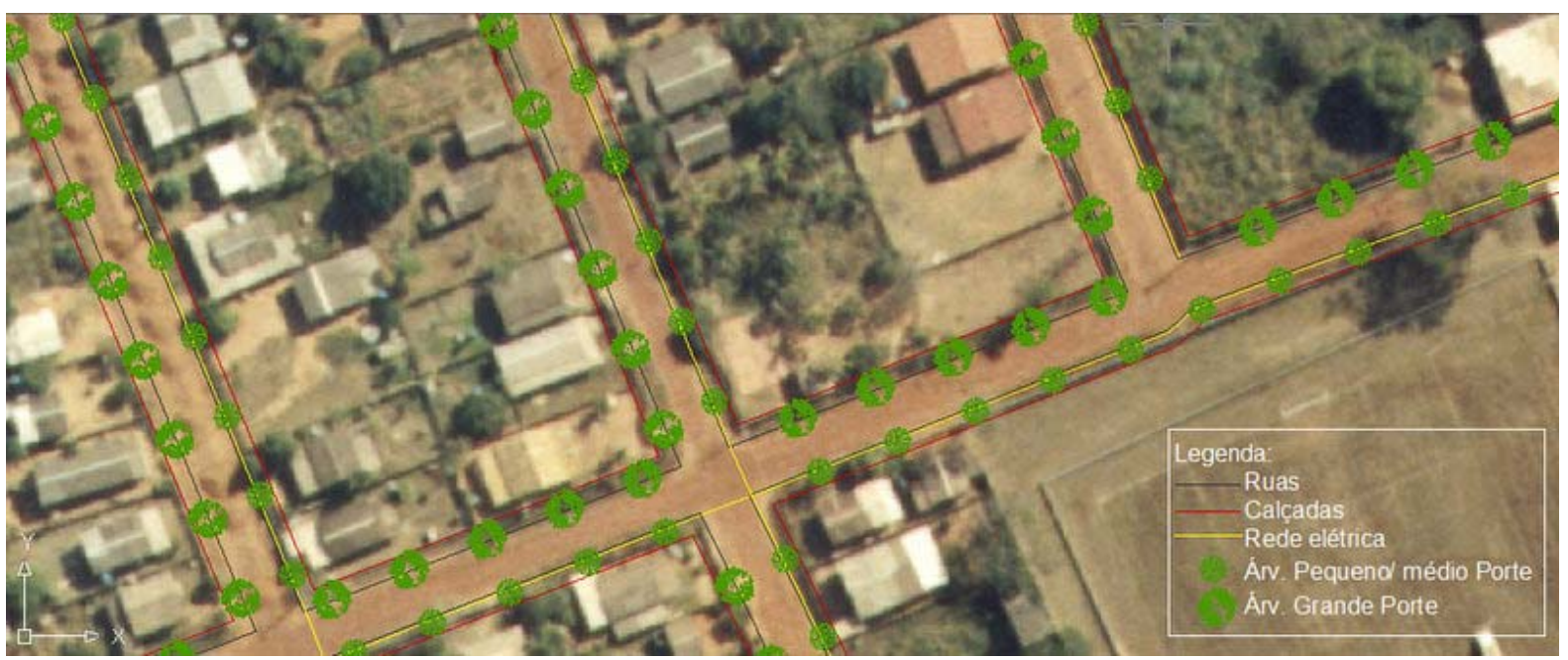

Foram desenhadas todas as ruas e calçadas, bem como posição da rede elétrica. Portanto, sob fiação elétrica recomenda-se o plantio de espécies de pequeno e médio porte, e no outro lado da via, que não houver fiação, podem ser plantadas espécies de grande porte. Nas grandes avenidas com canteiros centrais, que no caso desta cidade há uma apenas, podem ser plantadas palmeiras.
Para realização de uma arborização urbana viária complementar é muito importante que sejam considerados estes e outros aspectos para que se possa obter êxito, maximizando os benefícios que podem ser gerados por um planejamento correto da vegetação urbana, dando ênfase especialmente às espécies nativas, características da região. 
A arborização viária de Senador Guiomard é bastante deficiente, com maioria das espécies de origem exótica, e alta frequência de indivíduos em poucas espécies. O índice de diversidade e de indivíduos por km de calçada indicam baixa diversidade de espécies e reduzida quantidade de árvores nas ruas da cidade.

Frente a isso, é de extrema necessidade o planejamento de uma re/arborização de forma a complementar as árvores existentes, com plantio de espécies nativas e adequadas para cada local de plantio. Técnicas de manejo da vegetação urbana, bem como o monitoramento por parte do poder público devem ser elaboradas e executadas, de forma que se possam maximizar os benefícios que a arborização pode oferecer. Estudos envolvendo espécies da região fitoecológica se mostram interessante, devido à necessidade de informações básicas de comportamento das espécies nativas em meio urbano.

\section{REFERÊNCIAS BIBLIOGRÁFICAS}

ACRE. Zoneamento Ecológico-Econômico (ZEE) Fase II: documento síntese - Escala 1:250.000. Rio Branco: SEMA, 2006. 356p.

ALMEIDA, D. N. de.; RONDON NETO, R. M. Análise da arborização urbana de duas cidades da Região Norte do Estado de Mato Grosso.Revista Árvore, Viçosa-MG, v. 34, n. 5, p. 889-906, 2010.

ANDREATTA, T. R.; BACKES, F. A. A. L.; BELLÉ, R. A.; NEUHAUS, M.; GIRARDI, L. B.; SCHWAB, N. T.; BRANDÃO, B. S. Análise da arborização no contexto urbano de avenidas de Santa Maria, RS. Revista da Sociedade Brasileira de Arborização Urbana, Piracicaba, v. 6, n. 1, p.36-50, 2011.

APG III. An update of the Angiosperm Phylogeny Group classification for the orders and families of flowering plants: APG III. BotanicalJournaloftheLinneanSociety,v. 161,p. 105-121, 2009.

ARAÚJO, A. C. de; RIBEIRO, I. A. M.; MORAIS, M. dos S.; ARAÚJO, J. de L. O. Análise quali-quantitativa da arborização no Bairro Presidente Médici, Campina Grande - PB. Revista da Sociedade Brasileira de Arborização Urbana, Piracicaba, v. 4, n. 1, p. 133-144, 2009.

BORTOLETO, S.; SILVA FILHO, D. F. da; SOUZA, V. C.; FERREIRA, M. A. de P.; POLIZEL, J. L.; RIBEIRO, R. de C. S. Composição e distribuição da arborização viária da Estância de Águas de São Pedro-SP. Revista da Sociedade Brasileira de Arborização Urbana, v. 2, n. 3, 2007.

COSTA, L. A.; HIGUCHI, A. Arborização de ruas de Manaus: avaliação qualitativa e quantitativa. Revista Árvore, ViçosaMG, v. 23, n. 2, p. 213-221, 1999.

DALY, D.; SILVEIRA, M. Primeiro catálogo da flora do Acre, Brasil. Rio Branco: EDUFAC, 2008. 555p.

DANTAS, I. C.; SOUZA, C. M. C. de. Arborização urbana na cidade de Campina Grande - PB: Inventário e suas espécies. Revista de Biologia e Ciências da Terra, v. 4, n. 2, 2004.

INSTITUTO BRASILEIRO DE GEOGRAFIA E ESTATÍSTICA. População: censo 2010. 2010. Disponível em: <http://www.ibge.gov.br/home/estatistica/populacao/censo2010/tabelas_pdf/total_populacao_acre.pdf >. Acesso: 14 mar. 2011.

GOMIDE, L. R.; SCOLFORO, J. R. S.; OLIVEIRA, A. D. Análise da diversidade e similaridade de fragmentos florestais nativos na bacia do Rio São Francisco, em Minas Gerais.Ciência Florestal,Santa Maria, v.16, n.2, p.127-144, 2006.

LIMA, R. M. C. e. SILVA JÚNIOR, M. C. Inventário da arborização urbana implantada na década de 60 no Plano Piloto, Brasília, DF. Revista da Sociedade Brasileira de Arborização Urbana, Piracicaba, v. 5, n 4, p. 110-127, 2010.

NOWAK, D. J.; DWYER, J. F.; CHILDS, G. Los beneficios y costosdelenverdecimiento urbano. In: KRISHNAMURTHY, L.; NASCIMENTO, J. R. (Org.). Áreas verdes urbanas em Latinoamérica y el Caribe. Chapingo, México: Univerdidad 
Autónoma Chapingo, 1998. cap.2, p. 17-38. Diponível em: <http://km.fao.org/uploads/media/areasverdesurbanasLAC.pdf> . Acesso em: 21 maio 2011.

PAIVA, A. V. de. Aspectos da arborização urbana do Centro de Cosmópolis - SP. Revista da Sociedade Brasileira de Arborização Urbana, Piracicaba v. 4, n. 4, p. 17-31, 2009.

PAIVA, A. V. de. et al. Inventário e diagnóstico da arborização urbana viária de Rio Branco, AC. Revista da Sociedade Brasileira de Arborização Urbana, Piracicaba, v.5, n.1, p.144-159, 2010.

RABER, A. P.; REBElATO, G. S. Arborização viária do município de Colorado, RS - Brasil: Análise qualiquantitativa.Revista da Sociedade Brasileira de Arborização Urbana, Piracicaba, v. 5, n. 1, p. 183-199, 2010.

RIBEIRO, F. C.; PAIVA, A. V. de. Levantamento de espécies arbóreas nativas com potencial para arborização urbana do Estado do Acre. In: CONGRESSO BRASILEIRO DE ARBORIZAÇÃO URBANA, 14., 2010, Bento Gonçalves.Anais...Bento Gonçalves: Sociedade Brasileira de Arborização Urbana, 2010.

ROCHA, R. T. da; LELES, P. S. dos S.; OLIVEIRA NETO, S. N. de. Avaliação de vias públicas em Nova Iguaçu, RJ: o caso dos Bairros Rancho Novo e Centro. Revista Árvore, Viçosa, MG, v.28, n.4, p.599-607, 2004.

ROSSATTO, D. R.; TSUBOY, M. S. F.; FREI, F. Arborização urbana na cidade de Assis-SP: uma abordagem quantitativa. Revista da Sociedade Brasileira de Arborização Urbana, Piracicaba, v. 3, n. 3, p. 1-16, 2008.

ROSSETTI, A. I. N.; PELLEGRINO, P. R. M.; TAVARES, A. R. As árvores e suas interfaces do ambiente urbano.Revista da Sociedade Brasileira de Arborização Urbana,Piracicaba,v.5, n.1, p.1-24, 2010.

SANCHOTENE, M. do C. C. Aspects of preservation, maintenance and management of the urban forest in Brazil.Arboriculture\&UrbanForestry, Champaign, n.20, v.1, 1994.

SANTOS, C. Z. A. dos; FERREIRA, R. A.; SANTOS, L. R.; SANTOS, L. I.; GRAÇA, D. A. S. da; GOMES, S. H.; PORTO NETO, W. de B.; CORREIA, T. S.; BOSCHESE, A. C. de B. Composição florística de 25 vias públicas de Aracaju - SE. Revista da Sociedade Brasileira de Arborização Urbana, Piracicaba, v. 6, n. 2, p. 125-144, 2011.

Silva, F. de A. S. Assistat 7.6. 2011. Departamento de Engenharia Agrícola, UFCG. Disponível em: $<$ http://www.assistat.com>. Acesso em: 10 jul. 2011.

SILVA FILHO, D. F. da; PIZETTA, P. U. C.; ALMEIDA, J. B. S. A. de; PIVETTA, K. F. L.; FERRAUDO, A. S. Banco de dados relacional para cadastro, avaliação e manejo da arborização em vias públicas. Revista Árvore, Viçosa, MG, v. 26, n. 5, p. 629-642, 2002.

SUCOMINE, N. M.; SALES, A. Caracterização e análise do patrimônio arbóreo da malha viária urbana centro do município de São Carlos-SP. Revista da Sociedade Brasileira de Arborização Urbana, Piracicaba, v. 5, n. 4, p. 128-140, 2010.

TEIXEIRA, I. F. Análise qualitativa da arborização de ruas do conjunto habitacional Tancredo Neves, Santa Maria - RS. Ciência Florestal,Santa Maria, v. 9, n. 2, 1999. 